\title{
Employment and Patient Satisfaction after Liver Transplantation
}

\author{
Christopher Cao, Dina Halegoua-DeMarzio*, Shady Guirguis, Crystal Chen, \\ Jonathan M. Fenkel and Steven Herrine
}

Department of Gastroenterology and Hepatology, Thomas Jefferson University Hospitals, Philadelphia, PA, USA

\begin{abstract}
Background and Aims: This study serves to revisit the effects of liver transplantation (LT) on employment in an era of improving survival outcomes post-transplant, and to identify areas of improvement in the transplant process to better optimize post-LT employment and patient satisfaction. Methods: Prospectively, patients who had undergone LT at a single tertiary LT center were surveyed in person and by e-mail. Primary outcomes included employment rate preand post-LT, annual salary, weekly hours worked, barriers to re-employment, and patient satisfaction. Results: Responses were collected and analyzed from 121 patients who underwent LT. Pre-LT, 68 (56.1\%) reported full-time employment, $13(10.7 \%)$ part-time employment, and 40 (33.1\%) unemployment. Post-LT, $26(21.4 \%)$ reported continued full-time employment, 18 (14.9\%) part-time employment, and $77(63.6 \%)$ unemployment. Average weekly work hours decreased post-LT (16.1 h/week vs. 39.9 h/week). Mean annual salaries decreased post-LT (17 earning salary $\geq \$ 40,000$ vs. 56 earning salary $\geq \$ 40,000)$. These outcomes differed from patient pre-LT expectations, with $81.0 \%$ of previously employed patients believing they would return to employment, resulting in decreased patient satisfaction. Patients working physically demanding jobs pre-LT were less likely to return to work. Reasons cited for lack of return to full employment included early fatigue and difficulty regaining physical strength. Conclusions: Re-employment rates remain low post-LT, which is particularly true for patients working physically active jobs. Fatigue is a significant barrier to re-employment and increased physical rehabilitation post-LT may prove to be beneficial. Patients should be given realistic expectations about return to employment prior to their LT.
\end{abstract}

Citation of this article: Cao C, Halegoua-DeMarzio D, Guirguis S, Chen C, Fenkel JM, Herrine S. Employment and patient satisfaction after liver transplantation. J Clin Transl Hepatol 2020;8(3):299-303. doi: 10.14218/JCTH.2020.00010.

Keywords: Liver; Transplant; Liver transplant; Employment; Patient satisfaction. Abbreviations: LT, liver transplant; MELD, model for end-stage liver disease; QoL, quality of life.

Received: 6 February 2020; Revised: 11 May 2020; Accepted: 21 June 2020

*Correspondence to: Dina Halegoua-DeMarzio, Gastroenterology and Hepatology, Thomas Jefferson University Hospitals, 132 South 10th Street, Main Building, Suite 480, Philadelphia, PA 19107, USA. Tel: +1-215-955-8900, Fax: +1-215503-2146, E-mail: Dina.Halegoua-DeMarzio@jefferson.edu

\section{Introduction}

Based on the Organ Procurement and Transplantation Network data as of 2020, 8896 total liver transplants (LTs) were performed in the USA in 2019, with the number of annual transplants continuing to rise. ${ }^{1}$ LT provides a definitive therapy for patients with decompensated liver disease and improves survival in patients with a model for end-stage liver disease (MELD) score greater than $15 .^{2}$ With advancements in surgical technique, perioperative care and improvements in immunosuppression over the past few decades, survival outcomes after LT have steadily improved with 1-, 3-, and 5-year survival rates in 2017 at $91 \%, 83 \%$ and $75 \%$ respectively. ${ }^{3}$

Restoration of post-transplantation quality of life (QoL) has become a major area of study. Both short-term and long-term QoL have been addressed in past literature, noting that patients report a satisfactory QoL after $\mathrm{LT}^{4-6}$ Specifically, employment has been one key measure in determining a patient's QoL and ability to return to societal activities. In 1995, assessment of 203 adult LT patients established that $57 \%$ of LT recipients were employed and $43 \%$ were unemployed; the main factor towards unemployment was not feeling well enough to work. ${ }^{7}$ In 2007, a separate survey of 308 patients found that approximately $71 \%$ of patients returned to work, whereas approximately $29 \%$ of patients remained unemployed. ${ }^{8}$ The most important factors affecting post-LT employment included overall health status post-LT, age at transplant, disability status prior to transplant, nature of decompensated liver disease (alcoholic liver disease vs. non-alcoholic liver disease), concurrent diabetes and nature of insurance coverage. ${ }^{8-11}$

As the overall post-LT survival rates have improved significantly over the past decade, there has been an increasing importance placed on patient satisfaction and employment after surgery. Our study objective was to provide a census of the employment status of patients after LT at a single urban university health care facility. We also aimed to evaluate patients' recovery expectations prior to their surgery and whether these expectations were met. Concurrently, barriers to employment or full return to activity post-operatively will be evaluated, in the hopes of gaining a better understanding how to better optimize employment post-LT and improve patient satisfaction.

\section{Methods}

This single-center prospective survey study included responses from patients who had undergone LT at Thomas Jefferson University Hospitals, Philadelphia, PA, USA. A total of 201 individuals were surveyed, yielding 161 responses for 
Cao C. et al: Employment after liver transplantation

a response rate of $80.0 \%$. Among the 161 responses, incomplete surveys were excluded, and thus a total of 121 results were analyzed in the study. Eligible participants included any living patient 18 years or older who had undergone LT at our institution. The vast majority of patients had undergone LT within the past 10 years of survey; seven patients had undergone LT between 10-20 years prior to survey and one patient had undergone LT more than 20 years prior to survey. Exclusion criteria included any patient who was unable to give consent or did not have the capacity to provide accurate data, as determined at the discretion of the in-person surveyor at the time of questionnaire administration. Primary outcome measured was employment rate preand post-LT, including pre- and post-LT mean salary and mean weekly hours worked. Secondary outcomes included perceived barriers to re-employment, re-employment rate as stratified by nature of employment (physical vs. non-physical), patient expectations of employment post-LT, and overall patient satisfaction. Institutional Review Board approval was obtained prior to initiation of this study (No. 12289).

Data collection by our investigators was performed either inperson at the follow-up transplant clinic appointments or via email through a HIPAA-compliant data collection service. Inperson surveys were completed during weekly transplant clinic visits, with no discrimination in the distribution of surveys: surveys were offered to any consentable adult patient; nonEnglish speakers were offered a translator service; and, patients lacking English literacy had the survey dictated to them. Online surveys were sent via e-mail and were limited to Englishspeaking patients with access to internet, who were consentable, and demonstrated English literacy. Cumulatively, 90 responses were collected in-person and 71 responses were collected by e-mail. Surveys were conducted over an 8-month period, from September 2017 to April 2018. Verbal or written consent was obtained prior to survey. Patient participation was voluntary with no compensation for participating in the study.

A standard questionnaire was used for data collection. It included a total of 22 questions with queries for patient demographics, reason for transplant, employment expectations after LT, employment status pre-LT and post-LT (including employment at time of survey, average hours worked weekly, and annual salary), perceived health status, and perceived barriers in returning to satisfactory QoL. Participants were stratified by salary into those earning $\$ 40,000$ or more and those earning less than $\$ 40,000$. A $\$ 40,000$ cut-off was chosen given the USA's average individual salary in 2017 being $\$ 44,564 .^{11}$

With regards to employment, patients were asked to provide their job description if applicable, and these results were sorted into two categories for analysis - employment involving physical exertion and employment that was predominantly stationary. Employment for the purposes of this study was defined as holding any job for pay at the time of the survey, including part-time or full-time employment. Part time employment was defined as working fewer than 30 hours per week. Patients were also given the option to fill out a comment box regarding their overall experiences to $L T$, including any barriers they experienced to re-employment. Responses regarding these barriers were collected and further subcategorized for analysis purposes. Patients were able to write in more than one barrier they experienced to full recovery.

Results of patient satisfaction questions were collected and evaluated using descriptive statistics, medians and means.

\section{Results}

We collected results from 161 living adult liver recipients, whose LTs had been performed at Thomas Jefferson University Hospitals, and 121 responses were acceptable for analysis. A total of 201 surveys were distributed. Demographics information (Table 1) included sex, age at transplant, ethnicity, marital status, and level of education. Mean age of transplant was 55.3 years and median age at transplant was 56 years. In the study, $47(38.8 \%)$ participants were female and $74(61.2 \%)$ participants were male. Ethnically, patients were predominantly Caucasian (75.2\%), followed by African American (18.2\%), Hispanic/Latino (5.0\%), and Asian/Pacific Islander $(1.7 \%)$. The majority of patients were married $(57.0 \%)$, followed by being single $(24.0 \%)$, separated $(12.4 \%)$ or in a relationship $(6.6 \%)$. The majority of patients completed a high school education $(46.3 \%)$, followed by undergraduate degree $(34.7 \%)$, graduate degree $(15.7 \%)$, no school $(1.7 \%)$ and middle school $(1.7 \%)$. The most common reasons for transplant were hepatitis $\mathrm{C}$ virus $(36.8 \%)$, alcohol-related liver disease $(24.0 \%)$, non-alcoholic steatohepatitis $(9.6 \%)$, primary sclerosing cholangitis $(9.6 \%)$, primary biliary cholangitis $(4.0 \%)$, and autoimmune disease $(3.2 \%)$. On the whole, $14.9 \%$ of cases were complicated by development of hepatocellular carcinoma at time of transplant.

Surveys were conducted at a mean of 44.0 months post-LT and median of 22 months post-LT (range of 1 month to 328 months). Of the 121 surveyed, 115 participants had undergone single organ transplant and 6 patients had undergone dual liver-kidney transplant. All were deceased donor transplant recipients. Prior to transplant, the most common liver decompensations included ascites ( $n=55,45.5 \%)$, esophageal varices ( $n=43,35.5 \%)$, hepatic encephalopathy ( $n=$ $40,33.1 \%)$, spontaneous bacterial peritonitis $(n=7,5.8 \%)$, and hepatorenal syndrome $(n=3,2.5 \%)$.

Pre-LT 68 recipients $(56.1 \%)$ reported full-time employment, $13(10.7 \%)$ reported part-time employment, and 40 $(33.1 \%)$ reported unemployment. Of the 81 previously employed participants, $47(58.0 \%)$ worked in a place of employment not requiring physical labor (including managerial or administrative positions) or were self-employed, and 34 respondents $(42.0 \%)$ worked in positions requiring physical activity. Pre-LT participants who were employed worked an average of $39.9 \mathrm{~h} /$ week. Financially, 45 individuals earned a mean annual salary over $\$ 40,000$.

Post-LT, 26 recipients $(21.4 \%)$ reported continued fulltime employment, 18 (14.9\%) reported part-time employment, and $77(63.6 \%)$ reported unemployment. Of the 81 study participants previously employed, 44 (54.3\%) remained employed post-LT. Of the 44 participants still employed, 35 (79.5\%) worked in less physically demanding jobs and 9 (20.4\%) worked in more physically demanding jobs. After surgery, patients still employed worked an average of $16.1 \mathrm{~h} /$ week. Financially, 17 participants earned a mean annual salary over $\$ 40,000$ post-LT (Table 2 ).

Barriers to returning to full QoL compared to pre-transplant were cited to be due to inability to regain physical strength and continued weakness for $57(47.1 \%)$ of the respondents, medical complications for $16(13.2 \%)$, depression or difficulty returning to healthy mental state for 12 $(9.9 \%)$, or difficulty taking medication or seeing a health care provider for $11(9.9 \%)$. Median time to part-time or full-time employment for those that did return to work was less than 6 months. 
Table 1. Demographic information of LT recipients

\begin{tabular}{|c|c|}
\hline Variable & Value \\
\hline \multicolumn{2}{|l|}{ Sex } \\
\hline Female & $47(38.8 \%)$ \\
\hline Male & $74(61.2 \%)$ \\
\hline \multicolumn{2}{|l|}{ Age in years } \\
\hline Mean & 55.3 \\
\hline Median & 56 \\
\hline \multicolumn{2}{|l|}{ Ethnicity } \\
\hline Caucasian & $91(75.2 \%)$ \\
\hline African American & $22(18.2 \%)$ \\
\hline Hispanic or Latino & $6(5.0 \%)$ \\
\hline Asian or Pacific Islander & $2(1.7 \%)$ \\
\hline Native American or American Indian & $0(0.0 \%)$ \\
\hline \multicolumn{2}{|l|}{ Marital status } \\
\hline Single & $29(24.0 \%)$ \\
\hline In a relationship & $8(6.6 \%)$ \\
\hline Married & $69(57.0 \%)$ \\
\hline Divorced & $15(12.4 \%)$ \\
\hline \multicolumn{2}{|l|}{ Education level } \\
\hline No school & $2(1.7 \%)$ \\
\hline Middle school & $2(1.7 \%)$ \\
\hline High school (partial) & $8(6.6 \%)$ \\
\hline High school (complete) & $48(39.7 \%)$ \\
\hline Undergraduate (partial) & $22(18.2 \%)$ \\
\hline Undergraduate (complete) & $20(16.5 \%)$ \\
\hline Graduate & $19(15.7 \%)$ \\
\hline \multicolumn{2}{|l|}{ Reason for transplant } \\
\hline Hepatitis B virus & $3(2.5 \%)$ \\
\hline Hepatitis C virus & $46(38.0 \%)$ \\
\hline Alcohol-related liver disease & $30(24.8 \%)$ \\
\hline Non-alcoholic steatohepatitis & $12(9.9 \%)$ \\
\hline Primary biliary cirrhosis & $5(4.1 \%)$ \\
\hline Primary sclerosing cholangitis & $12(9.9 \%)$ \\
\hline Autoimmune disease & $4(3.3 \%)$ \\
\hline Other or cryptogenic & $9(7.4 \%)$ \\
\hline \multicolumn{2}{|l|}{ Insurance coverage } \\
\hline Medicare & $36(29.8 \%)$ \\
\hline Medicaid & $6(5.0 \%)$ \\
\hline $\begin{array}{l}\text { Private or Employer Purchased } \\
\text { Insurance }\end{array}$ & $79(65.3 \%)$ \\
\hline \multicolumn{2}{|l|}{ Time since transplant in months } \\
\hline Mean & 44 \\
\hline Median & 23 \\
\hline
\end{tabular}

Patient's employment outcomes were different from the participant expectations prior to transplant, with $59.5 \%$ of previously employed patients believing they would return to full-time employment and $21.4 \%$ believing they would return to part-time employment. Up to $41.3 \%$ of participants were satisfied with their post-LT employment status, $19.0 \%$ were unsatisfied with their post-LT employment status, and $39.7 \%$ declined to respond. Up to $71.9 \%$ of participants felt they had adequate external support and did not require additional rehabilitation help, while $4.1 \%$ of participants felt they had adequate external support and $24.0 \%$ of respondents declined to respond.

With regards to health status post-LT, 16 (13.2\%) of respondents reported excellent health, 34 (28.1\%) reported very good health, $45(37.2 \%)$ reported good health, 26 $(21.5 \%)$ reported fair health, and $0(0 \%)$ reported poor health. With regards to immunosuppressive medication, of the 121 patients, $94(77.7 \%)$ were taking tacrolimus, 15 $(12.4 \%)$ were taking sirolimus, $21(17.4 \%)$ were taking mycophenolate, $5(4.1 \%)$ were taking cyclosporine, and 6 $(5.0 \%)$ were taking prednisone.

\section{Discussion}

Liver transplantation serves to increase survival time and improve QoL in patients with decompensated liver disease at higher MELD scores. ${ }^{3}$ Functional status in LT recipients has been shown to be better in patients who were employed after transplant compared to those who were unemployed post-operatively. ${ }^{12}$ Unfortunately, past studies have demonstrated a considerable decrease in employment after LT. Favorable factors for post-LT employment have been younger age, male sex, Caucasian race, and employment prior to transplant. Factors found to negatively impact employment have included older age, female gender, presence of alcohol-related liver disease, associated diabetes, or lack of insurance. ${ }^{8-10}$

Our survey study of 121 patients took place over one decade after the related publication by Saab et al. ${ }^{8}$ Despite improved overall survival rates after graft as compared to 10 years ago, ${ }^{12}$ our study's findings indicate a continued low reemployment rate post LT. Post-LT, a total of $36.3 \%$ of patients reported full- or part-time employment at time of survey, with a post-LT employment rate of $54.3 \%$ in those who were previously employed. This re-employment rate remains similar to numbers cited in prior studies. Employment rates after other organ transplants have also been reviewed in literature and are similar to the employment rate we gathered for LT recipients: $26-36.8 \%$ in heart transplant recipients, ${ }_{1}^{13,14} 38.0 \%$ in lung transplant recipients, ${ }^{15}$ and $39.4-56.2 \%$ in kidney transplant recipients. ${ }^{16,17}$

Furthermore, there is a decrease in the average number of hours worked weekly (39.9 h/week pre-LT vs.16.1 h/week post-LT), suggesting that those who do return to work have a decreased workload compared to pre-transplant. Inability to work a full-time position is reflected in mean annual salaries; while 45 patients earned an annual salary of greater than $\$ 40,000$ pre-LT, only 17 individuals earned the same salary or greater than $\$ 40,000$ after transplant. Given the mean annual individual salary in the USA of $\$ 44,564$ in $2017,{ }^{11} 62.2 \%$ of participants previously earning a salary above the median income dropped below this threshold after LT.

A predominant reason cited in our survey for difficulty returning to full employment was weakness and decreased exercise tolerance in approximately $40 \%$ of respondents; other barriers to returning to work included dealing with depression and anxiety, encountering other medical complications, or endorsing inadequate control of pain. Notably, 
Cao C. et al: Employment after liver transplantation

Table 2. Employment status of patients pre- and post-LT

\begin{tabular}{|c|c|c|}
\hline Characteristics & Pre-LT & Post-LT \\
\hline \multicolumn{3}{|l|}{ Employment status } \\
\hline Full-time & $68(56.2 \%)$ & $26(21.5 \%)$ \\
\hline Part-time & $13(10.7 \%)$ & $18(14.9 \%)$ \\
\hline Unemployed & $40(33.1 \%)$ & $77(63.6 \%)$ \\
\hline \multicolumn{3}{|c|}{ Annual income if employed pre-LT in \$ } \\
\hline$<20,000$ & $11(13.4 \%)$ & $43(52.4 \%)$ \\
\hline $20,000-39,999$ & $15(18.3 \%)$ & $12(14.6 \%)$ \\
\hline $40,000-59,999$ & $22(26.8 \%)$ & $10(12.2 \%)$ \\
\hline $60,000-79,999$ & $14(17.1 \%)$ & $6(7.3 \%)$ \\
\hline $80,000-99,999$ & $6(7.3 \%)$ & $6(7.3 \%)$ \\
\hline$>100,000$ & $14(17.1 \%)$ & $7(8.5 \%)$ \\
\hline Mean hours working per week & 39.9 & 16.1 \\
\hline \multicolumn{3}{|c|}{ Employment expectations if employed pre-LT } \\
\hline Full employment & $25(59.5 \%)$ & \\
\hline Partial employment & $9(21.4 \%)$ & \\
\hline No employment & $8(19.0 \%)$ & \\
\hline Declined to answer & 39 & \\
\hline \multicolumn{3}{|c|}{ Satisfaction with employment status } \\
\hline Yes & & $50(41.3 \%)$ \\
\hline No & & $23(19.0 \%)$ \\
\hline Declined to answer & & $48(39.7 \%)$ \\
\hline \multicolumn{3}{|l|}{ Need for external support } \\
\hline Yes & & $87(71.9 \%)$ \\
\hline No & & $5(4.1 \%)$ \\
\hline Declined to answer & & $29(24.0 \%)$ \\
\hline
\end{tabular}

while $58.0 \%$ of respondents initially worked in jobs requiring physical activity pre-LT, only $20.4 \%$ of respondents worked in physically demanding jobs post-LT; fewer respondents working physically active jobs were able to return to work in a meaningful manner after transplant compared to participants working in less physically strenuous fields. This finding corresponds with the biggest barriers faced by our respondents - an inability to regain strength and increased fatigue. Interestingly, approximately $72 \%$ of all respondents did not feel that they needed additional external support from family members, physicians, or social workers. Contrary to these opinions, the use of physical rehabilitation to decrease fatigue has been studied in physical therapy literature, with results demonstrating that severe fatigue after LT was $22 \%$ to $53 \%$ lower than that at the start of physical rehabilitation. ${ }^{18}$

In the written response box, a majority of respondents cited that their expectations of employment post-LT did not match reality. A total of $80.9 \%$ of respondents who were previously employed believed that they would return to work in a full-time or part-time capacity; in actuality, only $54.3 \%$ were re-employed in some capacity. Participants expressed the desire to have been more informed of possible challenges to recovery, prior to their transplant, especially with regards to the difficulty of re-employment.

Compared to prior studies, there continues to be a considerable decrease in employment rate after transplant, including decreased number of work hours as well as a significant drop in annual wage. From our study, the biggest barrier in returning to full-time employment was inability to regain physical form; the need for more physical rehabilitation is evident in the increased amount of unemployment for respondents who were working in physically active fields pre-LT compared to those working less physically demanding jobs pre-LT. With regards to patient satisfaction, a considerable number of respondents did not feel that their expectations for functional status and re-employment status matched reality post-LT. Better management of patient expectations prior to surgery including a thorough explanation of expected difficulties with physical rehabilitation and re-employment may improve patient satisfaction.

Limitations of this study include being unable to correlate particular barriers to re-employment with mean time elapsed from surgery, which would have allowed for further clarification of challenges faced at each step of the recovery process doing so may help reduce generalizability. Additionally, sampling bias may be a factor in our survey study, as we only surveyed patients who followed-up in transplant clinic as well as patients who responded to our e-mail survey. Furthermore, it is difficult to assess patients' pre-transplant expectations of recovery after surgery given that patients were surveyed many years after their procedures, raising the possibility of recall bias. Finally, a sizeable proportion of our respondents who underwent LT had a diagnosis of hepatocellular 
carcinoma. These patients are generally healthier pre-LT and receive transplants due to MELD exception points; this may have skewed post-LT responses with regards to recovery.

Emphasis should be placed on providing patients with a realistic expectation that they may not return to work; patients should be made aware that fatigue is a prominent reason for unemployment and physical rehabilitation after transplant has been proven to decrease fatigue, despite patient opinion of not needing additional external support. This is particularly true for respondents working in physically strenuous fields. Further studies correlating use of physical rehabilitation to improve fatigue with return to employment may prove beneficial in improving QoL after transplant.

\section{Acknowledgments}

This work was supported in part by Health Resources and Services Administration contract 234-2005-37011C. The content is the responsibility of the authors alone and does not necessarily reflect the views or policies of the Department of Health and Human Services, nor does mention of trade names, commercial products, or organizations imply endorsement by the U.S. Government.

\section{Funding}

None to declare.

\section{Conflict of interest}

The authors have no conflict of interests related to this publication.

\section{Author contributions}

Study concept and design (DHM, CC), acquisition of data (DHM, CC, SG, CC), analysis and interpretation of data (DHM, CC, SG, $\mathrm{CC}, \mathrm{JF}, \mathrm{SH})$, drafting of the manuscript (DHM, CC), critical revision of the manuscript for important intellectual content (DHM, CC, SG, CC, JF, SH), study supervision (DHM).

\section{References}

[1] Annual Report of the U.S. Organ Procurement and Transplantation Network and the Scientific Registry of Transplant Recipients: Transplant Data 1994-2020.
[2] Merion RM, Schaubel DE, Dykstra DM, Freeman RB, Port FK, Wolfe RA. The survival benefit of liver transplantation. Am J Transplant 2005;5:307-313. doi: $10.1111 / j .1600-6143.2004 .00703 . x$.

[3] Bentley TS, Phillips S]. 2017 U.S. organ and tissue transplant cost estimates and discussion. Available from: https://spingolaspeaks.net/wp-content/uploads/2018/01/2017-transplant-report.pdf.

[4] Desai R, Jamieson NV, Gimson AE, Watson CJ, Gibbs P, Bradley JA, et al. Quality of life up to 30 years following liver transplantation. Liver Transpl 2008;14:1473-1479. doi: 10.1002/It.21561.

[5] Hunt CM, Tart JS, Dowdy E, Bute BP, Williams DM, Clavien PA. Effect of orthotopic liver transplantation on employment and health status. Liver Transpl Surg 1996;2:148-153. doi: 10.1002/It.500020211.

[6] Sahota A, Zaghla H, Adkins R, Ramji A, Lewis S, Moser J, et al. Predictors of employment after liver transplantation. Clin Transplant 2006;20:490-495. doi: 10.1111/j.1399-0012.2006.00511.x.

[7] Adams PC, Ghent CN, Grant DR, Wall WJ. Employment after liver transplantation. Hepatology 1995;21:140-144. doi: 10.1002/hep.1840210124.

[8] Saab S, Wiese C, Ibrahim AB, Peralta L, Durazo F, Han S, et al. Employment and quality of life in liver transplant recipients. Liver Transpl 2007;13:13301338. doi: $10.1002 /$ It. 21247.

[9] Bravata DM, Olkin I, Barnato AE, Keeffe EB, Owens DK. Employment and alcohol use after liver transplantation for alcoholic and nonalcoholic liver disease: a systematic review. Liver Transpl 2001;7:191-203. doi: 10. $1053 /$ jlts.2001.22326.

[10] Rongey C, Bambha K, Vanness D, Pedersen RA, Malinchoc M, Therneau TM, et al. Employment and health insurance in long-term liver transplant recipients. Am J Transplant 2005;5:1901-1908. doi: 10.1111/j.1600-6143.2005.00961.x.

[11] Usual weekly earnings of wage and salary workers fourth quarter. 2017. Available from: https://www.bls.gov/news.release/pdf/wkyeng.pdf.

[12] Huda A, Newcomer R, Harrington C, Keeffe EB, Esquivel CO. Employment after liver transplantation: a review. Transplant Proc 2015;47:233-239. doi: 10.1016/j.transproceed.2014.10.022

[13] Kristen AV, Ammon K, Koch A, Dösch AO, Erbel C, Celik S, et al. Return to work after heart transplantation: discrepancy with subjective work ability. Transplantation 2009;87:1001-1005. doi: 10.1097/TP.0b013e31819ca1ee.

[14] White-Williams C, Jalowiec A, Grady K. Who returns to work after heart transplantation? J Heart Lung Transplant 2005;24:2255-2261. doi: 10. $1016 / j$.healun.2005.08.006.

[15] Suhling $H$, Knuth $C$, Haverich A, Lingner $H$, Welte T, Gottlieb J. Employment after lung transplantation-a single-center cross-sectional study. Dtsch Arztebl Int 2015;112:213-219. doi: 10.3238/arztebl.2015.0213.

[16] Danuser B, Simcox A, Studer R, Koller M, Wild P. Employment 12 months after kidney transplantation: An in-depth bio-psycho-social analysis of the Swiss Transplant Cohort. PLoS One 2017;12:e0175161. doi: 10. 1371/journal.pone.0175161.

[17] D'Egidio V, Mannocci A, Ciaccio D, Sestili C, Cocchiara RA, Del Cimmuto A, et al. Return to work after kidney transplant: a systematic review. Occup Med (Lond) 2019;69:412-418. doi: 10.1093/occmed/kqz095.

[18] van den Berg-Emons RJ, van Ginneken BT, Nooijen CF, Metselaar HJ, Tilanus HW, Kazemier G, et al. Fatigue after liver transplantation: effects of a rehabilitation program including exercise training and physical activity counseling. Phys Ther 2014;94:857-865. doi: 10.2522/ptj.20130402. 